\title{
Enhanced autophagic flux by endoplasmic reticulum stress in human hepatocellular carcinoma cells contributes to the maintenance of cell viability
}

\author{
TAI MA ${ }^{1,2}$, YUAN-YUAN LI ${ }^{1}$, JIE ZHU ${ }^{1}$, LU-LU FAN $^{1}$, WEI-DONG DU ${ }^{3}$, \\ CHANG-HAO WU ${ }^{4}$, GUO-PING SUN ${ }^{1}$ and JIA-BIN LI ${ }^{2}$
}

\begin{abstract}
Departments of ${ }^{1}$ Oncology and ${ }^{2}$ Infectious Disease, The First Affiliated Hospital of Anhui Medical University, Hefei, Anhui 230022; ${ }^{3}$ State Key Laboratory Incubation Base of Dermatology, Ministry of National Science and Technology, Anhui Medical University, Hefei, Anhui 230032, P.R. China; ${ }^{4}$ Department of Biochemistry and Physiology, University of Surrey, Guildford GU2 7XH, UK
\end{abstract}

Received March 22, 2013; Accepted April 26, 2013

DOI: $10.3892 /$ or.2013.2474

\begin{abstract}
Endoplasmic reticulum (ER) stress and autophagy are important adaptive responses in eukaryotes. The aim of this study was to investigate the autophagic responses in hepatocellular carcinoma (HCC) cells under ER stress and the effect of autophagy on cell survival and death. The human HCC cell line HepG2 was stimulated with tunicamycin to induce ER stress. Cell viability was detected using the Cell Counting Kit-8. The accumulation of autophagic compartments was observed using transmission electron microscopy. The expression of ER and autophagy-related proteins was assessed by western blotting. Autophagic flux was assessed by microtubule-associated protein 1-light chain 3 (MAP1-LC3) turnover assay in the presence of chloroquine to inhibit lysosomes. HepG2 cells subjected to the ER stress presented a significant accumulation of autophagosomes and increased conversion of LC3-I to LC3-II as well as enhanced autophagic flux as detected by the LC3 turnover assay. Inhibition of autophagy with 3-methyladenine facilitated ER stress-related cell death. We conclude that ER stress enhances the autophagic flux in HepG2 cells, which may contribute to the maintenance of cell viability.
\end{abstract}

Correspondence to: Professor Jia-Bin Li, Department of Infectious Disease, The First Affiliated Hospital of Anhui Medical University, 218 Jixi Road, Hefei, Anhui 230022, P.R. China

E-mail: 1ijiabin948@vip.sohu.com

Professor Guo-Ping Sun, Department of Oncology, The First Affiliated Hospital of Anhui Medical University, 218 Jixi Road, Hefei, Anhui 230022, P.R. China

E-mail: sunguoping@ahmu.edu.cn

Key words: endoplasmic reticulum stress, autophagy, hepatocellular carcinoma cells, cell survival

\section{Introduction}

In eukaryotes, autophagy is a physiological response for the cell to undergo intracellular protein degradation and organelle turnover. It is one of the intrinsic cellular properties for maintaining cellular energy homeostasis under nutrition deficiency and stress. Recent progress has further extended the investigation of autophagy to tumorigenesis and cancer therapy. However, whether it represents a procancer or anticancer mechanism is far beyond our understanding (1). Autophagy reflects a complicated cellular process in hepatocellular carcinoma (HCC), a common cancer in Chinese and Asian populations (2). Deficiency/attenuation of autophagic function or downregulation of autophagy-related genes (ATGs), key regulator genes in autophagy, were significantly associated with the occurrence or poor prognosis of HCC (3-5). However, autophagy appears to mediate chemotherapy resistance as noted in in vitro experiments. For example, inhibition of autophagy was found to facilitate the killing of HCC cells by chemical drugs (6-14). This is of importance in clinical implications, as multidrug resistance (MDR) is one of the detrimental characteristics of HCC (2). An imminent task in cancer research is to elucidate the role of autophagy in HCC cells under variable microenvironments before we can address whether the process of autophagy may become a potential target for HCC therapy.

The high rate of proliferation and other adverse factors inherent in cancer cells usually result in an overload of endoplasmic reticulum (ER), leading to accumulation of misfolded and/or unfolded proteins in ER, a condition referred to as 'ER stress'. An unfolded protein response (UPR) is subsequently evoked to alleviate this stress by activating a group of signal transduction pathways and the transcription of genes. Tunicamycin (TM) is an antibiotic, which blocks the formation of $\mathrm{N}$-acetylglucosamine-lipid intermediates, thereby preventing glycosylation and maturation of proteins (15). TM is widely accepted as an ER stress stimulus since it induces the accumulation of unfolded proteins in the ER lumen. In $\mathrm{HCC}$, a number of environmental factors such as hypoxia, viral 
infection, chemicals or radiation stimulation can trigger ER stress (16-21). Moreover, ER stress is involved in several signal pathways related to hepatocellular proliferation, survival and apoptosis (22-24).

ER stress and autophagy in HCC often share the same stimuli $(10,18,21,25,26)$. Yet, whether or not ER stress itself triggers autophagy remains unknown, and the role of ER stress and autophagy in HCC cell survival and death is still unsolved. The aim of this study was to investigate autophagic responses in the human HCC cell line HepG2 under ER stress stimulation and its consequent effect on cell survival and death.

\section{Materials and methods}

Reagents. TM from Streptomyces sp. (cat. no. T7765), 3-methyladenine (3-MA; cat. no. M9281), chloroquine diphosphate salt (CQ; cat. no. C6628) and rapamycin (2.5 mg/ml in DMSO, cat. no. R8781) were purchased from Sigma-Aldrich (USA). To prepare stock solutions, 3-MA and CQ were dissolved in sterile ultrapure water, while TM was dissolved in DMSO with a final concentration of DMSO in the culture medium no more than 1/1,000 (v/v). Earle's balanced salt solution (EBSS) and Dulbecco's modified Eagle's medium (DMEM) were obtained from Invitrogen (USA); fetal bovine serum (FBS) was obtained from HyClone. The Cell Counting Kit-8 (CCK-8) was purchased from Dojindo Laboratories (Japan). The primary antibodies used for western blot analysis were antiLC3 antibody (cat. no. PM036; MBL Co., Ltd.); anti-Beclin 1 antibody (cat. no. ab16998), anti-GRP78 BiP antibody (cat. no. ab53068; both from Abcam, Inc., USA) and anti-caspase-3 antibody (cat. no. 9662; Cell Signaling Technology).

Cell culture. The HCC cell line HepG2 was obtained from the Cell Bank of Shanghai Institute for Biological Science, Chinese Academy of Sciences. Cells were routinely cultured in DMEM supplemented with $10 \%$ (v/v) FBS and maintained in a humidified incubator with $5 \% \mathrm{CO}_{2}$ at $37^{\circ} \mathrm{C}$.

Cell proliferation and viability analysis. Cell proliferation assays were performed using CCK-8. Re-suspended cells were seeded onto 96-well plates at a concentration of $10^{4}$ cells/well, and incubated for $24 \mathrm{~h}$ to allow adherence. The cells were then exposed to TM for the indicated concentrations and time points. For the inhibition assay, a stock solution of the autophagic inhibitors (3-MA or CQ) or an equal volume of PBS was added into the culture medium $1 \mathrm{~h}$ prior to TM application. The final concentrations of 3-MA and CQ were $5 \mathrm{mmol} / \mathrm{l}$ and $5 \mu \mathrm{g} / \mathrm{ml}$, respectively. After incubation, cell medium in each well was substituted with $100 \mu \mathrm{l}$ pre-prepared $\mathrm{WST}^{\circledR}-8$ solution (dilution of 1:10 in fresh DMEM); the plate was then incubated for an additional $1 \mathrm{~h}$ at $37^{\circ} \mathrm{C}$. Absorbance at $450 \mathrm{~nm}$ for WST-8 formazan was measured using the Elx800 absorbance microplate reader (BioTek Instruments, Inc). Triplicate measurements were made for each treatment subgroup in one plate, and the average optical density (OD) of the three wells was calculated. The average $\mathrm{OD}_{450 \mathrm{~nm}}$ of another two cell-free wells reserved in each plate was calculated as the background value. The cell viability was calculated according to the formula: $\%$ viability $=\left(\mathrm{OD}_{450 \mathrm{~nm}}\right.$ treated cells $-\mathrm{OD}_{450 \mathrm{~nm}}$ background) / ( $\mathrm{OD}_{450 \mathrm{~nm}}$ control cells - $\mathrm{OD}_{450 \mathrm{~nm}}$ background) x 100
At least three independent experiments were performed to generate the mean data for each intervention.

Transmission electron microscopy (TEM). Electron microscopy is a traditional and reliable method to observe autophagic compartments $(27,28)$. We performed TEM to demonstrate autophagosome formation in HepG2 cells after ER stress stimulation. Briefly, HepG2 cells were grown in 100-mm-diameter dishes. Following treatment with DMEM (control), EBSS, $1 \mu \mathrm{g} / \mathrm{ml}$ rapymycin or $2.5 \mu \mathrm{g} / \mathrm{ml} \mathrm{TM}$ for the indicated time periods, respectively, cells were collected and centrifuged at 3,000 rpm. Cell pellets were primarily fixed in a solution with $2.5 \%$ glutaraldehyde (v/v) overnight, and then in $1 \%$ osmium tetraoxide $(\mathrm{v} / \mathrm{v})$ for $1 \mathrm{~h}$ for secondary fixation. After dehydration in a series of concentrations of ethanol, the cells were finally embedded in Epon 812 . Ultrathin $(70 \mathrm{~nm})$ sections were cut on an NOVA ultramicrotome (LKB, Sweden), stained with uranyl acetate (saturated aqueous solution) and lead acetate, and then examined under a transmission electron microscope (JEM-1230; Jeol Ltd., Japan).

Western blot analysis. Briefly, cells were washed with pre-cooled PBS twice and lysed on ice for $30 \mathrm{~min}$ in RIPA lysis buffer containing $50 \mathrm{mmol} / \mathrm{l}$ Tris- $\mathrm{HCl}$ (pH 7.4), $150 \mathrm{mmol} / 1 \mathrm{NaCl}, 1 \mathrm{mmol} / 1$ phenylmethylsulfonyl fluoride (PMSF), $1 \mathrm{mmol} / 1$ ethylene diamine tetraacetic acid (EDTA), $0.1 \%$ sodium dodecyl sulfate (SDS), $1 \%$ Triton X-100 and $1 \%$ sodium deoxycholate. Lysates were centrifuged at $12,000 \mathrm{rpm}$ for $10 \mathrm{~min}$ at $4^{\circ} \mathrm{C}$. The supernatant was transferred into a new tube; the protein concentration was determined using BCA protein assay. Lysates were incubated with $2 \mathrm{X}$ Laemmli sample buffer (Bio-Rad, Hercules, CA, USA) and heated for $10 \mathrm{~min}$ at $95^{\circ} \mathrm{C}$. The proteins from each sample were separated by sodium dodecyl-sulfate-polyacrylamide gel electrophoresis (SDS-PAGE), and transferred onto polyvinylidene difluoride (PVDF) membranes (Millipore, Bedford, MA, USA). Membranes were blocked for $2 \mathrm{~h}$ at room temperature in PBS containing 5\% defatted milk powder and washed with Tris-buffered saline/Tween-20 (TBST) three times, then incubated overnight at $4{ }^{\circ} \mathrm{C}$ with the diluted primary antibody (anti-LC3, 1:1,000; anti-GRP78, 1:2,000; anti-Beclin 1, 1:1,000; anti- $\beta$-actin, 1:500) in PBST. After washing in PBST, the membranes were then incubated for $1 \mathrm{~h}$ at room temperature with the secondary antibody (goat anti-mouse-HRP, 1:10,000). The immunoreactive proteins were detected using the enhanced chemiluminescence (ECL) kit (Pierce) and the chemiluminescent signals were captured by ImageQuant ${ }^{\mathrm{TM}}$ LAS-4000 Mini Imager (Fuji, Japan). For quantitative analysis, the integrated density of each band was obtained using ImageJ software (US National Institutes of Health).

Data analysis. At least three independent experiments were performed for the numerical variables unless otherwise stated. Data are expressed as the means \pm standard deviation in each group. Student's t-test and one-way ANOVA were used to examine the differences between two or multiple groups, respectively. Statistical tests were performed using SPSS 15.0 software. A probability-value $<0.05$ was considered to indicate a statistically significant result. 

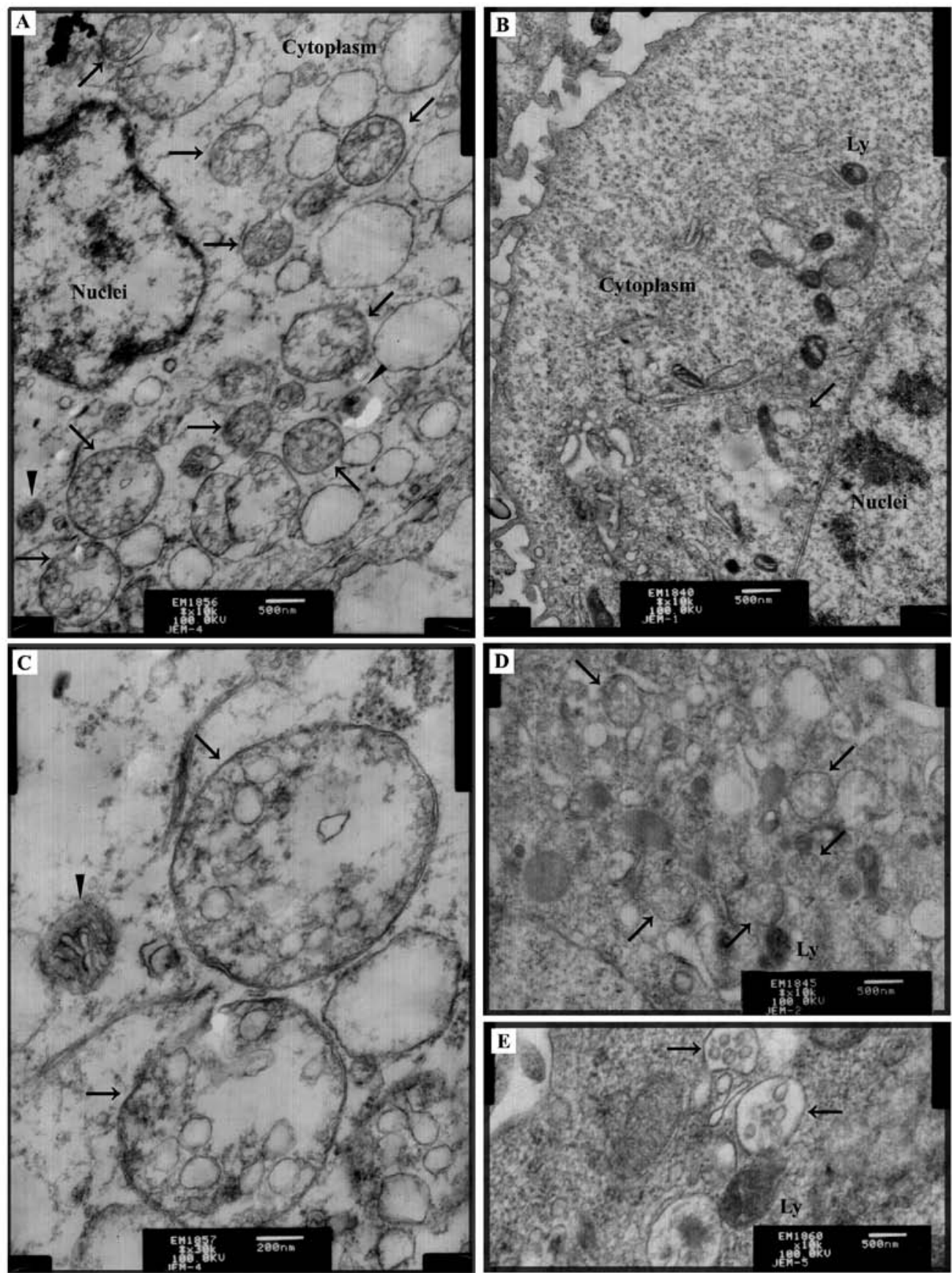

Figure 1. Autophagic compartments in HepG2 cells. Ultrastructure observed under transmission electron microscopy. Ly, lysosome; arrows and triangles indicate autophagosomes and autolysomes, respectively. (A) TM $(2.5 \mu \mathrm{g} / \mathrm{ml})$ incubation for $24 \mathrm{~h} ; \mathrm{x} 10,000$. (B) Control group; x 10,000. (C) Magnified autophagosome from panel A; x30,000. (D) EBSS incubation for $6 \mathrm{~h}$; x10,000. (E) Rapamycin (1 $\mu \mathrm{g} / \mathrm{ml})$ incubation for $24 \mathrm{~h}$; x10,000.

\section{Results}

ER stress triggers accumulation of autophagic compartments in HepG2 cells. After exposure to TM $(2.5 \mu \mathrm{g} / \mathrm{ml})$ for $24 \mathrm{~h}$, TEM revealed that there was a greater number of autophagic compartments accumulated in the TM-treated cells (Fig. 1A) when compared with that in the non-treated cells (Fig. 1B); the latter also showed rare autophagic compartments. Autophagosomes were recognized as double membrane vacuolar structures containing cytoplasmic contents (Fig. 1A and C). Other types of autophagic compartments such as autolysosomes also appeared in the form of membrane vacuolar structures containing high-density materials (Fig. 1A). Two known autophagy inducers, starvation medium EBSS (Fig. 1D) and rapamycin (Fig. 1E), acting via amino acid deprivation and mTOR inhibition, respectively, were used as the positive controls, and accumulation of autophagic compartments in response to these interventions clearly indicated autophagy.

ER stress induces LC3 conversion and enhances autophagic flux in HepG2 cells. Western blot analysis was used to detect several key proteins involved in the process of autophagic flux and ER stress. GRP78, a resident protein of ER, was used as 


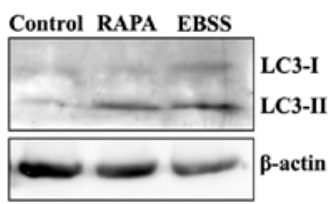

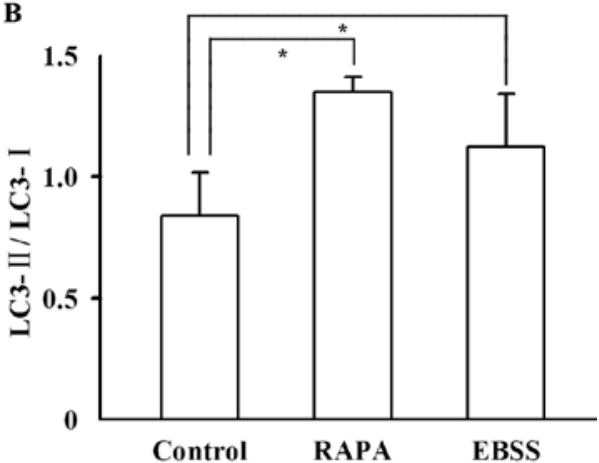

D

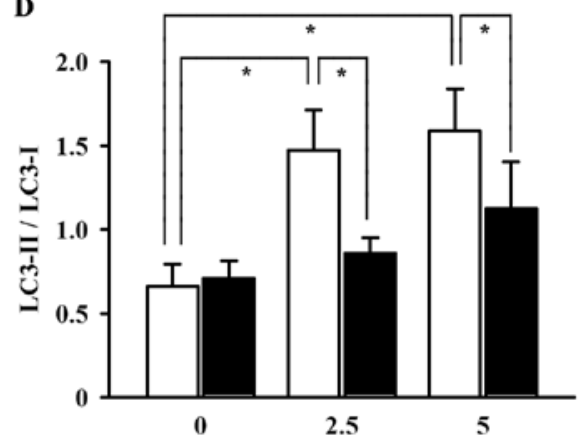

$\mathrm{TM}(\mu \mathrm{g} / \mathrm{ml})$

3-MA(-)

3-MA(+)

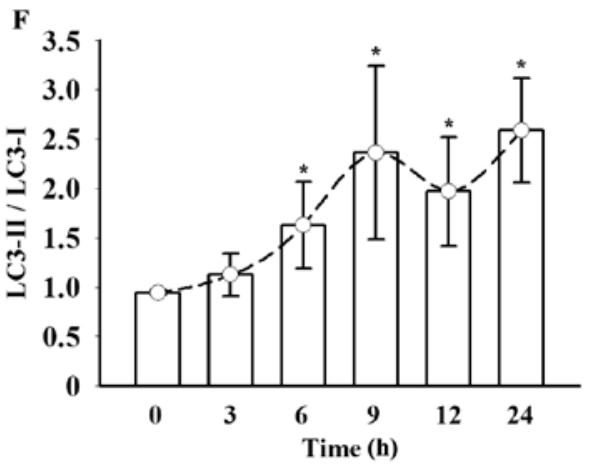

Figure 2. LC3 conversion assay in ER-stressed HepG2 cells by western blotting. (A) Positive controls used in the autophagic LC3 conversion. Cells were treated with DMEM, EBSS for $6 \mathrm{~h}$ or rapamycin (RAPA) $(1 \mu \mathrm{g} / \mathrm{ml})$ for $24 \mathrm{~h}$, respectively; $\beta$-actin was used as the loading control. (B) Quantitative analysis of data from A. Integrated density of LC3-I and LC3-II bands expressed as arbitrary units measured by ImageJ software; LC3-II/LC3-I ratio for each group was calculated; " $\mathrm{P}<0.05$, comparison between the indicated two groups. (C) Cells were treated with indicated concentrations of TM for $12 \mathrm{~h}$ in the absence or presence of 3-MA (5 mmol/1). LC3 together with GRP78 and Beclin 1 were detected. (D) Quantitative analysis of LC3 conversion data from C; " $\mathrm{P}<0.05$, comparison between the indicated two groups. (E) Cells were treated with $2.5 \mu \mathrm{g} / \mathrm{ml} \mathrm{TM}$ for different time durations. (F) Quantitative analysis of LC3 conversion data from $\mathrm{E},{ }^{*} \mathrm{P}<0.05$, comparison with the 0 h group.

a molecular marker of ER stress. The microtubule-associated protein 1-light chain 3 (MAP1-LC3, LC3), also known as Atg8 in yeast, is cleaved by the Atg4 homologue to form LC3-I (29). Upon induction of autophagy, LC3-I conjugates to phosphatidylethanolamine (PE) to become LC3-II which anchors to the autophagosomal membrane throughout the process of autophagosomal maturation until degradation by lysosomes (30). Although LC3-II is a reliable marker of autophagosomes (31), the process of conjugation of LC3-I to PE to form LC3-II is more indicative of the autophagic reaction. Thus, the conversion of LC3-I to LC3-II is considered to be a surrogate of autophagy induction. Both proteins can be detected by protein electrophoresis and immunoblotting and the LC3 ratio (calcu- lated by scanned intensities of LC3-II/LC3-I in each group) is a measure of autophagic LC3 conversion (32).

Initially, we performed two positive controls for autophagy detection: the two well-known autophagy inducers EBSS (incubated for $6 \mathrm{~h}$ ) and rapamycin $(1 \mu \mathrm{g} / \mathrm{ml}$ for $24 \mathrm{~h})$. Both induced overexpression of LC3-II and an increase in the LC3 ratio (Fig. 2A and B). Consequently, decreased expression of LC3-I and increased expression of LC3-II were observed in HepG2 cells after ER stress stimulation (Fig. 2C). Accordingly, the LC3 ratio (LC3-II/I) was elevated in the cells treated with 2.5 and $5 \mu \mathrm{g} / \mathrm{ml} \mathrm{TM}$ when compared to the ratio in the unstressed cells $(\mathrm{P}<0.05)$. This indicates an increase in conversion of LC3-I to LC3-II after ER stress (Fig. 2D). 3-MA, a 


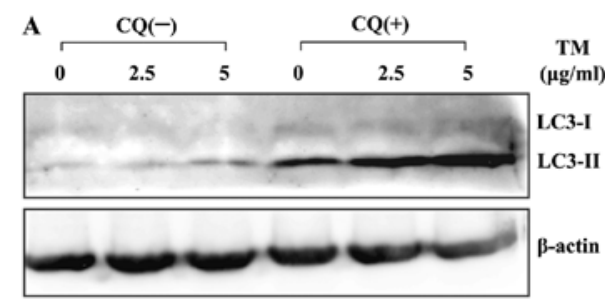

B
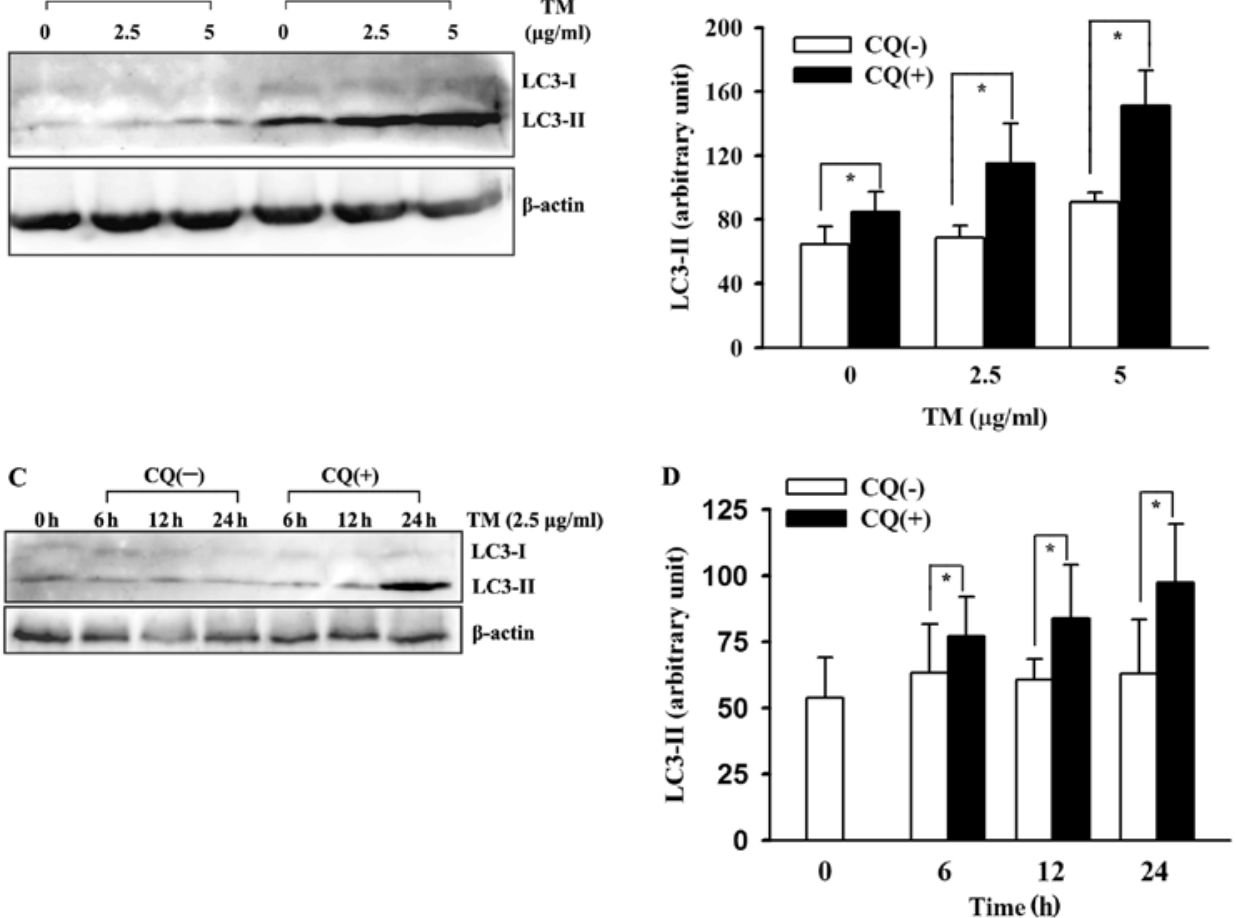

Figure 3. Effect of CQ on LC3 turnover analysis in HepG2 cells after ER stress. (A) Cells were treated with TM (2.5 or $5 \mu \mathrm{g} / \mathrm{ml})$ for $24 \mathrm{~h}$ in the presence or absence of CQ $(5 \mu \mathrm{g} / \mathrm{ml})$. (B) Quantitative analysis of intensities of bands in A; band intensities of LC3-II expressed as arbitrary units. "P<0.05, comparison between the indicated two groups. (C) Cells were treated with $2.5 \mu \mathrm{g} / \mathrm{ml} \mathrm{TM}$ for different durations in the presence or absence of CQ (5 $\mu \mathrm{g} / \mathrm{ml})$. (D) Quantitative analysis of LC3-II intensity data from $\mathrm{C}$ expressed as arbitrary units. " $\mathrm{P}<0.05$, comparison between the indicated two groups.

A

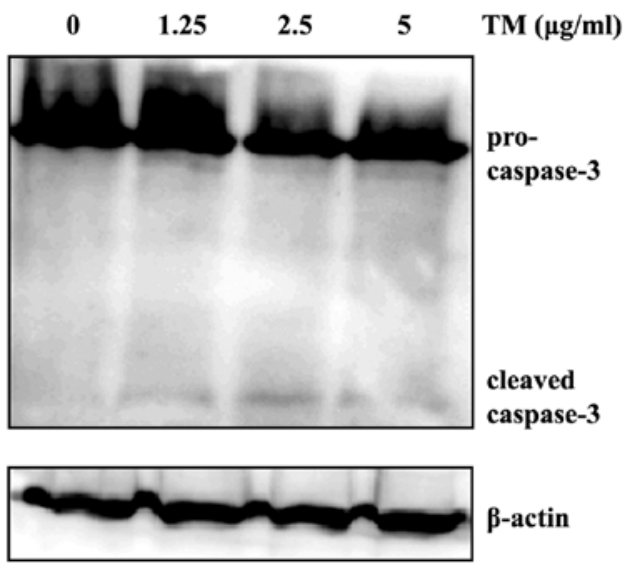

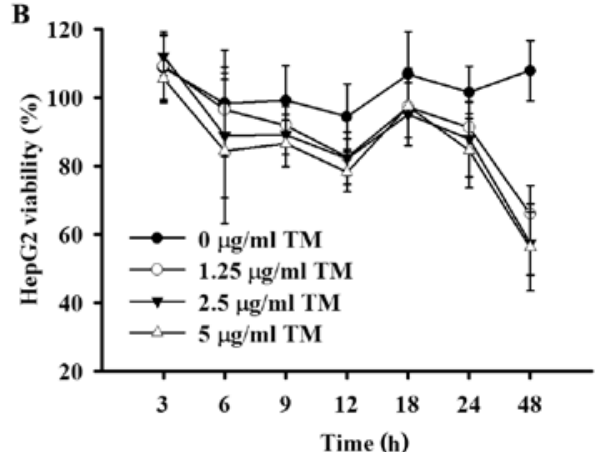

Figure 4. ER stress-induced HepG2 cell death. (A) Caspase-3 cleavage in HepG2 after treatment with TM (1.25, 2.5 and $5 \mu \mathrm{g} / \mathrm{ml})$ for 48 h, as detected by western blotting. (B) Changes in HepG2 viability after incubation with TM $(1.25,2.5 \mathrm{and} 5 \mu \mathrm{g} / \mathrm{ml})$ for the indicated time durations. At least three independent experiments were performed; data are presented as means \pm SD.

PI3K class III inhibitor (also named Vps34) suppressed the LC3 conversion which suggests the involvement of PI3K ClassIII/Vps34 in the observed autophagy by ER stress. In parallel, we ascertained the occurrence of ER stress in HepG2 cells through evidence of GRP78 overexpression after TM stimulation (Fig. 2C). Furthermore, we also demonstrated a time-dependent increase in autophagy induction in the ER-stressed HepG2 cells by treating the cells with TM for 3, 6, 9, 12 and $24 \mathrm{~h}$ (Fig. 2E and F). Another autophagy-related protein, Beclin 1, appeared to be unaffected either by the ER stressor or co-existing 3-MA (Fig. 2C).
An important consideration in autophagy detection was whether or not the observed accumulation of autophagosomes (or its surrogate, LC3-II) was indicative of an authentic autophagy induction or simply the blockage of autophagosomal degradation in the lysosomes. Thus, performing an 'autophagic flux' assay by using a lysosomal inhibitor was necessary to distinguish between the aforementioned two possibilities (31). We performed 'LC3 turnover assay' to demonstrate autophagic flux enhancement in the ER-stressed HepG 2 cells. Briefly, we pretreated the cultured cells with lysosomal inhibitor CQ for $1 \mathrm{~h}$ before TM, then compared 


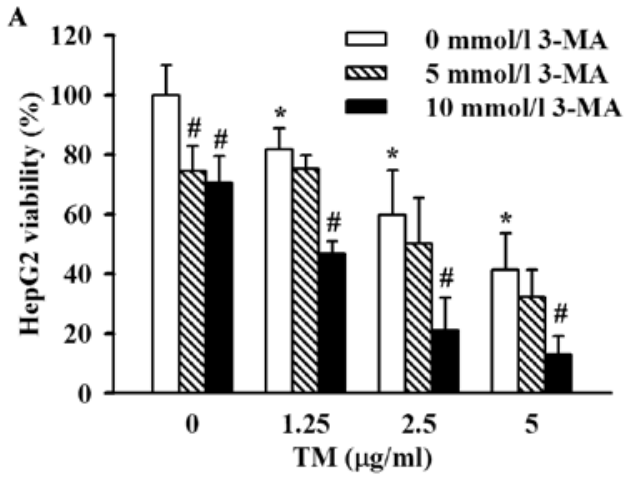

B

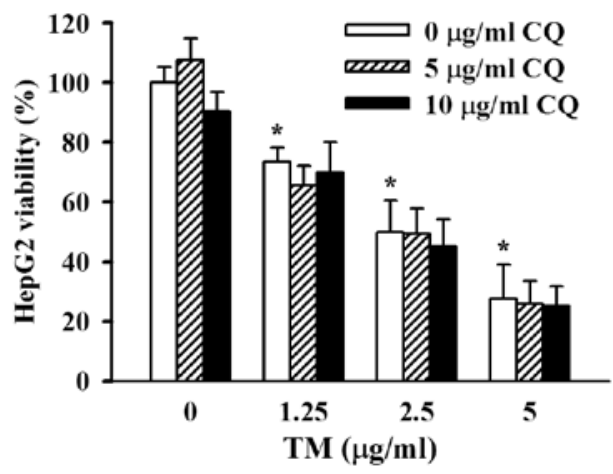

Figure 5. Influence of autophagy inhibitors (3-MA or CQ) on cell viability of ER-stressed HepG2 cells. Data are presented as means \pm SD. Cells were incubated with different concentrations of TM for $48 \mathrm{~h}$ in the presence or absence of (A) 3-MA (5 or $10 \mathrm{mmol} / \mathrm{l})$ or (B) CQ (5 or $10 \mu \mathrm{g} / \mathrm{ml})$ and cell viability was measured by CCK- 8 . ${ }^{*} \mathrm{P}<0.05$, compared to ' $0 \mu \mathrm{g} / \mathrm{ml} \mathrm{TM}$ and $0 \mathrm{mmol} / 1$ 3-MA' subgroup. ${ }^{\text {"}} \mathrm{P}<0.05$, compared to ' $0 \mathrm{mmol} / 1$ 3-MA subgroup' for each group of different TM dosage.

changes in LC3 expression with those in the absence of CQ. The results showed a marked increase in LC3-II accumulation after lysosomal inhibition. As shown in Fig. 3, the upregulated LC3-II was lysosomal-dependent. This indicated an authentic induction of autophagy in the HepG2 cells by TM, not a defect in autophagosomal degradation.

Role of autophagy in the maintenance of viability of ER-stressed HepG2 cells. ER-stress associated cell death was demonstrated in HepG2 cells by the cleavage and activation of caspase-3 after treatment with $1.25,2.5$ or $5 \mu \mathrm{g} / \mathrm{ml} \mathrm{TM}$ for $48 \mathrm{~h}$ (Fig. 4A). Furthermore, results of the CCK-8 test also showed a decrease in HepG2 cell viability after ER stress stimulation, and the cell viability was well correlated with the dose and duration of TM incubation (Fig. 4B). We confirmed induction of autophagy in the ER-stressed HepG2 cells. To further ascertain the role of the observed autophagy in ER-stress related cell death and survival, we introduced two autophagy inhibitors which blocked the autophagic pathway at different sites; 3-MA, an inhibitor of phosphatidyl inositol 3-kinase, blocks initiation of autophagic vesicles and CQ, a lysosomal inhibitor, affects the downstream process of autophagy. In the presence of 3-MA (5 or $10 \mathrm{mmol} / \mathrm{l}$ at final concentrations), $48 \mathrm{~h}$ of TM stimulation induced a more significant decrease in cell viability than that without 3-MA co-incubation, and $10 \mathrm{mmol} / \mathrm{l} 3-\mathrm{MA}$ exerted a greater degree of cell viability suppression than $5 \mathrm{mmol} / \mathrm{l}$ 3-MA (Fig. 5A). The data described above showed that inhibition of autophagy facilitated ER stress-associated cell death, i.e., enhancement of autophagy induced by ER stress contributed to cell viability maintenance. However, CQ did not appear to exert an effect on the viability of ER-stressed HepG2 cells (Fig. 5B), although lysosome inhibition was considered to a certain degree as a dysfunction of autophagy.

\section{Discussion}

Induction of autophagy in HepG2 cells by TM. Although both UPR and autophagy have been interpreted as stress responses in eukaryotes, direct evidence linking ER stress to autophagy was first published in yeast (33), following by evidence in normal and transformed human cell lines (34-39). However, the so-called 'increase in autophagy' in most published studies (in fact, accumulation of autophagosomes) can be attributed not only to induction of autophagy but also blockage of the degradation in lysosomes (31). Few studies reportedly have performed lysosomal inhibition assay to verify the fluency of the whole autophagic flux. Thus, the purpose of the present study was to demonstrate the induction of autophagy and enhancement of autophagic flux in HepG2 cells following ER stress, by observing ultramicroscopic accumulation of autophagosomes, alterations in biochemical markers and functional enhancement of autophagic degradation in lysosomes.

We confirmed an authentic induction in autophagy and enhancement of autophagic flux in the ER-stressed HepG2 cells. However, in another study, ER stress-induced autophagic degradation of apoB in the HepG2 cell line was unable to be demonstrated (39). Yet, we did not refute our theory as the authors of that study also demonstrated enhancement of autophagic apoB degradation in two other hepatoma cell lines, and alternative degradation pathways for apoB may coexist in HepG2 cells; the propensity of apoB degradation varies in different cell lines.

ER stress signals to autophagy are still unresolved. PI3K class III/Vps34 is clearly involved in ER stress-induced autophagy in HepG2 cells, as 3-MA can suppress autophagy induction by TM in HepG2 cells. We also detected Beclin 1 expression in HepG2 cells. Decreased expression of autophagy protein Beclin 1 is associated with poor prognosis of HCC (5), and induction of autophagy in prostate cancer cells involves interaction between Bcl-2 and Beclin 1 at the ER (40). Yet, we failed to find a difference in its expression between ER-stressed and unstressed cells; possibly a distinct signaling pathway exists in ER stress triggered autophagic flux in HCC.

Role of ER stress-induced autophagy in the survival of HepG2 cells. ER stress leads to accumulation of unfolded protein, and autophagy is associated with the degradation of protein and organelles (41). Based on this finding, ER stress and related autophagy are cancer cell survival mechanisms in response to hypoxia, nutrition deficiency and stress. However, autophagic cell death (ACD, type II cell death) was proposed recently by the Nomenclature Committee on Cell Death (NCCD) as a new sub-routine of cell death (42), yet the role of autophagy in cell death has not yet been clarified (43-47). One study reported that ER stress-induced autophagy exerts differential effects on cell survival: pro-survival effects in cancer cells and prodeath effects in normal cells (34). Our results demonstrated 
a decrease in cell survival in the TM-treated HepG2 cells in the presence of the autophagic inhibitor 3-MA, indicating that a pro-survival effect of autophagy played a dominant role in ER-stressed HepG2 cells, similar to that in neuroblastoma cells (38). Autophagy inhibition induced by chemical drugs in HepG2 cells and other hepatocarcinoma cell lines also exhibited enhancement of cell death $(48,49)$, but whether ER stress was involved in these mechanisms is unknown.

We did not observe an effect of the lysosomal acidification inhibitor, CQ, which blocks the downstream process of autophagy. This finding suggests that the linkage between autophagy signaling and death signals may be located upstream in the process of autophagy, as the targets of 3-MA were located at the initiation of autophagy. In fact, ER itself can function as a switching point in autophagy and death by interaction between $\mathrm{Bcl}-2$ family proteins occurring on the ER membrane $(50,51)$.

In conclusion, ER stress in HepG2 cells elicits enhancement of autophagic flux. This contributes to the maintenance of cell viability. Our results may help to eluciate the understanding of carcinogenesis and drug resistance of HCC.

\section{Acknowledgements}

We thank Professor Qi-Xing Zhu of Anhui Medical University for providing the experimental platform and encouragement to complete the study. This study was supported by grants from National Natural Science Foundation of China (no. 81071986 and no. 81272739), and by a key project of the Anhui Provincial Office of Education, China (no. KJ2011A154). C.W. gratefully acknowledges support from the Biotechnology and Biological Sciences Research Council (BBSRC) (BB/G015554/1; BB/ I025379/1).

\section{References}

1. Levine B: Cell biology: autophagy and cancer. Nature 446 745-747, 2007.

2. Forner A, Llovet JM and Bruix J: Hepatocellular carcinoma. Lancet 379: 1245-1255, 2012.

3. Kisen GO, Tessitore L, Costelli P, et al: Reduced autophagic activity in primary rat hepatocellular carcinoma and ascites hepatoma cells. Carcinogenesis 14: 2501-2505, 1993.

4. Qu X, Yu J, Bhagat G, et al: Promotion of tumorigenesis by heterozygous disruption of the beclin 1 autophagy gene. J Clin Invest 112: 1809-1820, 2003.

5. Ding ZB, Shi YH, Zhou J, et al: Association of autophagy defect with a malignant phenotype and poor prognosis of hepatocellular carcinoma. Cancer Res 68: 9167-9175, 2008.

6. Song J, Qu Z, Guo X, et al: Hypoxia-induced autophagy contributes to the chemoresistance of hepatocellular carcinoma cells Autophagy 5: 1131-1144, 2009.

7. Du H, Yang W, Chen L, et al: Role of autophagy in resistance to oxaliplatin in hepatocellular carcinoma cells. Oncol Rep 27: 143-150, 2012.

8. Ding ZB, Hui B, Shi YH, et al: Autophagy activation in hepatocellular carcinoma contributes to the tolerance of oxaliplatin via reactive oxygen species modulation. Clin Cancer Res 17: 6229-6238, 2011.

9. Xie BS, Zhao HC, Yao SK, et al: Autophagy inhibition enhances etoposide-induced cell death in human hepatoma G2 cells. Int J Mol Med 27: 599-606, 2011.

10. Guo XL, Li D, Hu F, et al: Targeting autophagy potentiates chemotherapy-induced apoptosis and proliferation inhibition in hepatocarcinoma cells. Cancer Lett 320: 171-179, 2012.

11. Shi YH, Ding ZB, Zhou J, et al: Targeting autophagy enhances sorafenib lethality for hepatocellular carcinoma via ER stressrelated apoptosis. Autophagy 7: 1159-1172, 2011
12. Shimizu S, Takehara T, Hikita H, et al: Inhibition of autophagy potentiates the antitumor effect of the multikinase inhibitor sorafenib in hepatocellular carcinoma. Int J Cancer 131: 548-557, 2012.

13. Liu YL, Yang PM, Shun CT, Wu MS, Weng JR and Chen CC: Autophagy potentiates the anti-cancer effects of the histone deacetylase inhibitors in hepatocellular carcinoma. Autophagy 6: 1057-1065, 2010.

14. Hui B, Shi YH, Ding ZB, et al: Proteasome inhibitor interacts synergistically with autophagy inhibitor to suppress proliferation and induce apoptosis in hepatocellular carcinoma. Cancer 118: 5560-5571, 2012.

15. Tkacz JS and Lampen O: Tunicamycin inhibition of polyisoprenyl $\mathrm{N}$-acetylglucosaminyl pyrophosphate formation in calf-liver microsomes. Biochem Biophys Res Commun 65: 248-257, 1975.

16. Koumenis C: ER stress, hypoxia tolerance and tumor progression. Curr Mol Med 6: 55-69, 2006.

17. Shuda M, Kondoh N, Imazeki N, et al: Activation of the ATF6, XBP1 and grp78 genes in human hepatocellular carcinoma: a possible involvement of the ER stress pathway in hepatocarcinogenesis. J Hepatol 38: 605-614, 2003.

18. Al-Rawashdeh FY, Scriven P, Cameron IC, Vergani PV and Wyld L: Unfolded protein response activation contributes to chemoresistance in hepatocellular carcinoma. Eur J Gastroenterol Hepatol 22: 1099-1105, 2010.

19. Xu Z, Jensen G and Yen TS: Activation of hepatitis B virus S promoter by the viral large surface protein via induction of stress in the endoplasmic reticulum. J Virol 71: 7387-7392, 1997.

20. Li B, Gao B, Ye L, et al: Hepatitis B virus $\mathrm{X}$ protein $(\mathrm{HBx})$ activates ATF6 and IRE1-XBP1 pathways of unfolded protein response. Virus Res 124: 44-49, 2007.

21. Sir D, Chen WL, Choi J, Wakita T, Yen TS and Ou JH: Induction of incomplete autophagic response by hepatitis $\mathrm{C}$ virus via the unfolded protein response. Hepatology 48: 1054-1061, 2008.

22. Wang HC, Huang W, Lai MD and Su IJ: Hepatitis B virus pre-S mutants, endoplasmic reticulum stress and hepatocarcinogenesis. Cancer Sci 97: 683-688, 2006.

23. Cho HK, Cheong KJ, Kim HY and Cheong J: Endoplasmic reticulum stress induced by hepatitis $B$ virus $X$ protein enhances cyclo-oxygenase 2 expression via activating transcription factor 4. Biochem J 435: 431-439, 2011.

24. Joyce MA, Walters KA, Lamb SE, et al: HCV induces oxidative and ER stress, and sensitizes infected cells to apoptosis in SCID/ Alb-uPA mice. PLoS Pathog 5: e1000291, 2009.

25. Sir D, Tian Y, Chen WL, Ann DK, Yen TS and Ou JH: The early autophagic pathway is activated by hepatitis B virus and required for viral DNA replication. Proc Natl Acad Sci USA 107: 4383-4388, 2010.

26. Mizui T, Yamashina S, Tanida I, et al: Inhibition of hepatitis $\mathrm{C}$ virus replication by chloroquine targeting virus-associated autophagy. J Gastroenterol 45: 195-203, 2010.

27. Ylä-Anttila P, Vihinen H, Jokitalo E and Eskelinen EL: Monitoring autophagy by electron microscopy in Mammalian cells. Methods Enzymol 452: 143-164, 2009.

28. Mizushima N, Yoshimori T and Levine B: Methods in mammalian autophagy research. Cell 140: 313-326, 2010.

29. He H, Dang Y, Dai F, et al: Post-translational modifications of three members of the human MAP1LC3 family and detection of a novel type of modification for MAP1LC3B. J Biol Chem 278: 29278-29287, 2003.

30. Kabeya Y, Mizushima N, Ueno T, et al: LC3, a mammalian homologue of yeast Apg8p, is localized in autophagosome membranes after processing. EMBO J 19: 5720-5728, 2000.

31. Klionsky DJ, Abeliovich H, Agostinis P, et al: Guidelines for the use and interpretation of assays for monitoring autophagy in higher eukaryotes. Autophagy 4: 151-175, 2008.

32. Karim MR, Kanazawa T, Daigaku Y, Fujimura S, Miotto G and Kadowaki M: Cytosolic LC3 ratio as a sensitive index of macroautophagy in isolated rat hepatocytes and H4-II-E cells. Autophagy 3: 553-560, 2007.

33. Yorimitsu T, Nair U, Yang Z and Klionsky DJ: Endoplasmic reticulum stress triggers autophagy. J Biol Chem 281: 30299-30304, 2006.

34. Ding WX, Ni HM, Gao W, et al: Differential effects of endoplasmic reticulum stress-induced autophagy on cell survival. J Biol Chem 282: 4702-4710, 2007.

35. Qin L, Wang Z, Tao L and Wang Y: ER stress negatively regulates AKT/TSC/mTOR pathway to enhance autophagy. Autophagy 6: 239-247, 2010. 
36. Kawakami T, Inagi R, Takano H, et al: Endoplasmic reticulum stress induces autophagy in renal proximal tubular cells. Nephrol Dial Transplant 24: 2665-2672, 2009.

37. Sakaki K, Wu J and Kaufman RJ: Protein kinase Ctheta is required for autophagy in response to stress in the endoplasmic reticulum. J Biol Chem 283: 15370-15380, 2008.

38. Ogata M, Hino S, Saito A, et al: Autophagy is activated for cell survival after endoplasmic reticulum stress. Mol Cell Biol 26 9220-9231, 2006.

39. Qiu W, Zhang J, Dekker MJ, et al: Hepatic autophagy mediates endoplasmic reticulum stress-induced degradation of misfolded apolipoprotein B. Hepatology 53: 1515-1525, 2011.

40. Lian J, Karnak D and Xu L: The Bcl-2-Beclin 1 interaction in (-)-gossypol-induced autophagy versus apoptosis in prostate cancer cells. Autophagy 6: 1201-1203, 2010.

41. Lum JJ, Bauer DE, Kong M, et al: Growth factor regulation of autophagy and cell survival in the absence of apoptosis. Cell 120: 237-248, 2005.

42. Galluzzi L, Vitale I, Abrams JM, et al: Molecular definitions of cell death subroutines: recommendations of the Nomenclature Committee on Cell Death 2012. Cell Death Differ 19: 107-120, 2012.

43. Levine B and Yuan J: Autophagy in cell death: an innocent convict? J Clin Invest 115: 2679-2688, 2005.

44. Kroemer G and Levine B: Autophagic cell death: the story of a misnomer. Nat Rev Mol Cell Biol 9: 1004-1010, 2008.
45. Wirawan E, Vanden Berghe T, Lippens S, Agostinis P and Vandenabeele P: Autophagy: for better or for worse. Cell Res 22: 43-61, 2012.

46. Denton D, Nicolson S and Kumar S: Cell death by autophagy: facts and apparent artefacts. Cell Death Differ 19: 87-95, 2012.

47. Cheng Y and Yang JM: Survival and death of endoplasmicreticulum-stressed cells: role of autophagy. World J Biol Chem 2 226-231, 2011.

48. Daniel F, Legrand A, Pessayre D, Vadrot N, Descatoire V and Bernuau D: Partial Beclin 1 silencing aggravates doxorubicinand Fas-induced apoptosis in HepG2 cells. World J Gastroenterol 12: 2895-2900, 2006.

49. Longo L, Platini F, Scardino A, Alabiso O, Vasapollo G and Tessitore L: Autophagy inhibition enhances anthocyanininduced apoptosis in hepatocellular carcinoma. Mol Cancer Ther 7: 2476-2485, 2008.

50. Rovetta F, Stacchiotti A, Consiglio A, et al: ER signaling regulation drives the switch between autophagy and apoptosis in NRK-52E cells exposed to cisplatin. Exp Cell Res 318: 238-250, 2012.

51. Szegezdi E, Macdonald DC, Ni Chonghaile T, Gupta S and Samali A: Bcl-2 family on guard at the ER. Am J Physiol Cell Physiol 296: C941-C953, 2009. 